\title{
School Management in the Midst of Educational Technology Advancement
}

\author{
Yosef Gebremeskel $^{1}$
}

${ }^{1}$ Addis Ababa University; College of Education and Behavioral Studies; Department of Educational Planning and Management.

\begin{tabular}{|c|c|}
\hline ARTICLE INFO & ABSTRACT \\
\hline $\begin{array}{l}\text { Keywords: } \\
\text { Educational Technology, } \\
\text { School Management. }\end{array}$ & $\begin{array}{l}\text { This qualitative study has been intended to explore school } \\
\text { management practices in the midst of educational technology } \\
\text { advancement. Case study research design has been employed to have } \\
\text { an in depth look at practices of a selected school on adopting } \\
\text { technology driven school management in a way that addresses the } \\
\text { type of technologies introduced and how they have contributed for } \\
\text { school management. Accordingly, the school has so far introduced } \\
\text { different educational technologies within short period of time. } \\
\text { Though positive roles of the introduced educational technologies on } \\
\text { improving the existing school management have been recognized by } \\
\text { regulatory bodies, further content and context based studies and } \\
\text { assessments need to be initiated in a way that enables expansion of } \\
\text { the school's best practices to other private and public schools in the } \\
\text { metropolitan. }\end{array}$ \\
\hline
\end{tabular}

\section{Introduction}

Technology is a long journey in life experience that creates opportunities for selfreliance. Countries that fail to exercise technology driven approaches can be deprived of their chances to industrialize and grow economically. Youths of a nation should be supported to be engaged in technological education as far as it is an inevitable way to realize success of the entire country.

Educational technology is all about improving quality of education through the application of modern technology. Educational technology involves instructional materials, methods and organization of work and relationships of participants in the educational process. The word technology takes its root from Greek word "techno" that stands for the willingness, skills and knowledge of the ways, skills, rules and tools whereas "logos" stands for science, word,

\footnotetext{
$\square$ Corresponding Author E-Mail Address: jojogreat2008@gmail.com
} 
learning or mental state. Different similar terms like educational equipment and AV resources are interchangeably used in place of educational technology (Stošić, 2015).

Educational technology focuses on process of people, procedures, ideas, devices, and organization for analyzing problems so that educators or students can devise, implement, evaluate and manage solutions to those problems involved in all aspects of human learning (Mayes, 2015).

Before deciding to use any sort of educational technology, it is very important to pay attention to its educational value, evaluate its appropriateness for knowledge acquisition, make sure the existence of interactions between the tool and its users and assess the positive effects gained by using the educational technology. Accordingly, there are five proposed areas that should be considered on applying educational technologies. These were educational value of the program, capacity of engaging students, being user friendly, the level of interactivity between students and the selected program and how much the software program tracks individual progress (Stošić, 2015).

As it has been indicated by Higgins, Xiao, \& Katsipataki (2012), technologically embedded education which is conducted in collaborative way (in pairs or small groups) has been found to be more effective than individualized learning. In addition to this, the writer has presented an empirical data that stated the use of technology driven education in short term interventions for some areas in curriculums rather than being implemented regularly. Remedial or tutorial use of technology to support students with special need, training educators in the way how technology can be used for improving class lessons by emphasizing on specific pedagogical aspects, using technology as a supplement instead of replacing existing teaching approaches and preparing subject specific intervention plans for implementing technologies in schools have been recommended by previous researches (Higgins et al., 2012).

Different researches like the one studied by Higgins et al., (2012) have tried to shade light on the contributions of technology embedded education. Higgins et al., (2012) reported that high performing schools were likely to invest more on equipping their educational system with different technologies.

Though there are different research findings that support the contributions of digital technologies for learning, convincing results are not yet in place in terms their roles on academic achievements. A certain educational technology which is helpful for some groups of students or some subjects may have detrimental effects on other groups or subjects. To this end, more studies are expected to identify where and how some technological interventions bring about positive changes in educational attainment. According to a study made by Schleicher, (2006) "More microstudies are needed within countries to explore the extent to which certain kinds of computer usage raise performance, and which kinds are most effective. At the same time, in countries where basic computer access is approaching universal, policy needs to turn its attention from providing the technology to ensuring that its usage is effective." (Schleicher, 2006, p 69).

In general terms, plenty of research findings have confirmed that technology induced education has results of positive changes in schools. Increased number of technological platforms 
along with different contexts has made research findings difficult to arrive at clear and specific implications on the roles of technology in education (Higgins et al. 2012).

These days, social networking is becoming fashion of the day. Currently, some educational institutions are taking major steps for reaching out to learners through social networking. According to Zaideieh (2012), educational endeavors which are made through social networking have reaped some benefits and challenges as well. Privacy, real friendship, taking up time and miscommunication are some of the major hindering features on utilizing social networking for educational purposes. In contrary to this, flexibility, repeatability and convenience and accessibility have been found to be the positive features of social networking in light of its role for improving quality of education.

Recently, many countries have taken the initiative to provide technology education as one subject. In some other countries, technology has taken up large portions in science curriculum. In different countries, technology education has been introduced in different Nature and Technology (in Denmark), Design and Technology (in UK), STEM (Science, Technology, Engineering and Mathematics in USA) and in some other countries has been named as Modern Information Technology and ICT. Some countries have preferred to focus mainly on the technical aspects of technology whereas the remaining countries have opted for emphasizing on human relations to technology, society and technology and so on (Sjøberg, 2002)

Today, through the evolution of web-based software programs, the world has been acquainted with a new online community called Curriki (www.curriki.com) that enabled educators to access and contextualize educational contents and lesson plans from the internet. The program aims at supporting disadvantaged teachers and students by availing high-quality educational quality free of charge (Murray, 2007)

Among different technology-driven innovations in education, inverted/flipped classroom that realized blended learning approach has created multifaceted modes of interaction between teachers and students. Interactive videos are digitally enriched materials with additional information beyond original contents. The capacity of interactive videos on accommodating additional resources has changed the linear nature of educational videos. This educational approach has changed the previous teacher led instructions into student led inquiry based learning. This has encouraged collaborative transfer of knowledge (Strecker, Kundisch, Lehner, Leimeister, \& Schubert, 2018)

Currently, educational technologists have been faced with different challenges which come from different areas including the internet, intra/interconnected devices and software products and services. On managing to score major advancements which are made on safeguarding the wealth of educational contents and collaborative learning activities, educational technologists are still confronted with ethical issues that include an ever increasing digital divide, system security, organizational and personal privacy issues. Maintaining uninterrupted and sustainable 
learning and instruction has also become a big challenge in the midst of technology explosion (Mayes, Natividad, Spector, 2015).

Among different stakeholders that exist in the education system, school leaders take the lion share responsibility on selecting the best type educational technologies and facilitate their usage in a planned and coordinated manner. Exploiting the maximum level of benefits from educational technology demands the capacity of creating and sharing a vision that gains ownership of all stake holders in schools. Effective education leaders are thought to be good at developing a shared vision that illustrates how technology supports learning in their schools; and on how to access the technology needed to harness education. Since leaders need to gather feedbacks from stake holders, they are expected to communicate using proper media and technology outlets that lets them collect concerns and suggestions (US Department of Education, 2017).

There are literatures that attribute successful integration of technology in education to effective leadership (e.g., Afshari et al. 2008; Dawson \& Rakes 2003). In an empirical study which was conducted in UK, Tearle (2003) came up with a new finding that school culture and "committed educational leadership" play key roles in ICT implementation. On the other hand a study made by Asegedom $(1998 ; 1999)$ has stressed on the key role of educational leaders for encouraging teachers to use educational technologies.

Availability of robust technology infrastructure is crucial to make digital learning environments happen. Leaders are responsible for all commitments in relation to infrastructure development and maintenance. Leaders assume a big responsibility to keep the technology infrastructure updated and assure the existence of necessary web content and social media platforms to support collaborative learning. In addition to this, leaders are expected to offer capacity building trainings for experts who create and maintain the technology infrastructure. Leaders also recognize the importance of building capacity programs for individuals who are responsible for creating and maintaining the technology infrastructure. All these efforts are made through profound planning and financial stewardship that strategically targeted at long term sustainability. Teachers and leaders facilitate collaborative inquiry to build the capacity of the whole staff through face to face, online and blended professional learning communities and networks (US Department of Education, 2017).

Majority of the countries in OECD (Organization for Economic Co-operation and Development) have developed their strategic plans by recognizing educational technology as driving force for the development of their respective societies. At the same time, most developing and least developed countries have identified the role of Information Communication Technology for poverty reduction strategies. In the current world, there is a general consent on the contributions of education, science, innovations and ICT for socio-economic development. International summit which was held in Geneva (2003) and Tunis (2006) have also underlined that ICT is an enabler for social and economic development in the world. Even though technology plays key role for global 
economy and cultural globalization, there are large concerns on some detrimental effects it can cause on quality of education (Kumpulainen, 2007).

As one of the countries that recognized the key role of technology driven education, Ethiopia has tried to introduce different technologically embedded educational approaches by launching plasma education and strengthening the ICT education as one subject especially at general secondary and preparatory level schools (Bitew, 2008). One of the specific objectives in the Education and Training Policy stated that education should be a supportive tool to develop traditional education; and for properly utilizing modern technology. Though the policy document has not mentioned what technologies need to be induced to improve educational organization and management, the educational support inputs section of the policy has capitalized on the special emphasis that should be given for popular participation, production, distribution, utilization, upkeep, care and safety of educational technologies in schools (Education and Training Policy,1994).

In light of all the above national and international realities, the current study has been designed to explore the existing school management practices in relation to the application of educational technology. Among different private schools which are found in Addis Ababa, Yeka sub-city; the study was conducted in "Golden Academy". The school which has been selected for the study caters formal education starting from grade 1 to 12 . Based on the data gathered from the school, it was founded in September 2016. In 2018/19 academic year, there are 486 male and 454 female students who are attending primary education (1-8). From grade 9-12, there are 124 male and 95 female students. Based on the report issued by Addis Zemen newsletter on Yekatit 4/2011 E.C, it has been recognized by Addis Ababa City Administration Education bureau as the only school that reached level 4 especially for its technologically embedded education.

\section{Statement of the Problem}

There are tremendous technological advancements in our day to day life experiences. Political, societal and economic aspects of life are becoming highly influenced by the accelerating changes in science and technology. The pace of technological advancement has brought a new political, social and economic era in the whole world. The existence of daily improving science and technology has become capable of creating a rapidly changing dynamic environment. Solutions made for problems occurring at earlier times have dramatically become obsolete due to technological changes in all aspects of human life. In the midst of all these technological changes, schools in general and school management in particular cannot remain unaffected from these overwhelming changes.

It is undeniable that, in our daily lives, we are overwhelmed by products and services which are the results of science and technology. Being a highly change sensitive sector, education and its governing documents are greatly influenced by every little technological advancements. In 
this scenario, change becomes an inevitable fact for all stake holders in the sector. At the same time, the way how challenges and opportunities are addressed becomes a critical issue.

Being one of the social sectors, education has currently been faced with unavoidable technological challenges and opportunities. Failing to address those challenges and opportunities can necessarily bring long lasting effects on its deliverables since educational contents and contexts cannot remain unaffected by the swiftly evolving science and technology advancement.

Ethiopia, as one of the emerging economies in the world, is trying to emphasize on enhancing, incorporating and supporting initiatives related to educational science and technology. Like all other nations in the world, the Ethiopian Education System cannot stay capsulated in the face of world-wide changes. The governing education document of the country (the Ethiopian Education and Training Policy, 1994) is currently facing multi-faceted technology related challenges and opportunities. Though many people still wrongly refer the Ethiopian Education and Training Policy as "new" until now, it is worth to critically examine whether or not its elements are "new" or "old".

My search for related literatures on the internet has ended up with large number of international studies which were made on how technology has affected teaching-learning process specifically and education in general terms. Studies that focused on school management in association with educational technology are almost hardly available. A study entitled "Reimagining the Role of Technology in Education" which was published by USA Department of Education in 2017 has at least tried to discuss educational leadership in the midst of changes on educational technologies. As far as my search is concerned, there are limited local researches (Woldab, (2014); Bitew, (2008) and Asegedom, (1999)) that specifically dealt with the general education in relation to advancements in educational technologies. Being different from its predecessors, the current study tries to shade light on the contributions of educational technologies for school management.

To explore the contributions of technological advancement on practices of educational management, the current study has been geared towards addressing the following research questions:-

1. What are the major educational technologies that exist in "Golden Academy" in relation to school management?

2. What are the contributions of educational technologies in "Golden Academy" for school management?

Compared with educational technologies which have been introduced in the schooling system, the attention given for the issue may have necessarily affected efficiency and effectiveness of educational managers to significant level. Ignoring the swiftly changing situation at hand may lead educational institutions to bear heavy costs by failing to attain their desired ultimate goals. 
Such research endeavors could make minor contributions for paving the way to address technological challenges and seek to expand opportunities.

Research Methodology and Design

The current study has tried to address the basic research questions by employing qualitative research methodology. The dominant qualitative research approach has been selected to deeply explore introductions and practices of different educational technologies at "Golden Academy". Among the different types of research designs in qualitative research methodology, I have opted for case study research design for its suitable nature on making an in-depth look at the central phenomenon. By narrowing the geographical scope of the study, detailed qualitative data were gathered from respondents in the selected research site ("Golden Academy"). As it has been proposed by the study released by Schleicher (2006), micro-studies have been encouraged to see how educational technologies bring about changes at grass root levels.

Research Participants

Two directors (one for the elementary and one for the secondary schools), a deputy director for the primary school, a STEM (Science, Technology, Engineering and Mathematics) teacher, an ICT teacher, a librarian and three teachers have participated in separate interview sessions. Apart from the above mentioned research participants, I have also taken part in the research as a non-participant observer by taking field notes and taking pictures from the research setting whenever I come across something which I thought might address the research questions.

\section{Sources of Data}

The current study has dwelt on empirical primary data from interview sessions, observations and documents which were found in the research setting. On the other hand, secondary data were collected from available sources on the internet mainly from google scholar. In addition to this, local documents including the countries Education and Training Policy have been consulted.

Data gathering Tools

Semi-structured interview questions and observation guide were used to gather primary data. Semi-structured interview questions were used to gather qualitative data from the interview sessions. At times when raised questions led to some relevant areas, probing questions were forwarded for further clarifications. During interview sessions, a tape recorder was used after taking permissions from respondents. Observation guide was also used to make sure those 
observations which have direct relations with the study could be recorded properly. At the same time, pictures were also taken to capture empirical evidences from the research setting.

Data Gathering Procedure and Data Analysis

Before directly delving into data gathering, I arranged a meeting with my gate keeper who has supported me in all my data gathering initiatives in the selected school. Following this, I reached an agreement with the gate keeper on my schedule for data gathering. Since the data of the research was purely qualitative, responses of participants during interview sessions were systematically recorded using tape recorder. Data which were gathered from observations in the school compound, offices, classrooms and documents were recorded using observation guide and mobile phone for capturing pictures. The recorded data were later transcribed properly immediately after I left the research setting so that both contents and contexts were not forgotten through time. Then, the transcribed qualitative data were given different codes so that they could be later categorized into different themes or categories. In all data gathering and analysis engagements, precautions were taken to follow ethical standards that include keeping responses confidential and respondents anonymous. Though the school has already become very popular for its technologically embedded educational system, it has been tried to give pseudo name in order to abide by confidentiality standards.

Results and Discussion

Technology vs. Strategic Planning and Organizational Culture

One of the key areas in today's educational management is related to developing well owned strategic plan among all stake holders. Along with communicating their strategic plans, schools are expected to create homogenous organizational culture using elements from their strategic plans. Communicating the strategic plan and its respective elements including Vision, Mission and Core values requires implementation of recent technological platforms (US Department of Education, 2017). Among these platforms, the most common and frequently used platform is developing web-site. During my visit at "Golden Academy", I have seen that the school's vision and mission statements have been posted at the gate of the main building in the school compound along with its core values. In addition to this, they have clearly elaborated their strategic direction in a promotional documentary film which was prepared in 2018 academic year. Taking these as a good starting point, the school director has admitted their limitation for not communicating other elements of their five year strategic plan through different technological approaches including a web-site. Though the school has not yet launched its web-site, large scale preparation is in place to organize future engagements in the area by hiring Cisco Certified Network Professional. According to the respondent, the preparation is already underway.

In the interview session which was held with one of the directors of the school, he has stated that they have started the business after setting a 25 year road map which has been cascaded into five years strategic plan. The strategic plan has been further translated into yearly operational plans. Based on the data gathered through observation and interview, the school has implemented balanced score card starting from strategic planning to individual basis plans and performance 
evaluations in the school. All the above mentioned planning and evaluation activities are communicated through hard copies (paper works). Evaluation check lists were posted on mounting boards. As is has been reported by one of the school directors, in the recent future, the school has figured out its where about on introducing technology for addressing planning and evaluation of communication media in the existing school context.

One of the most interesting parts in relation to the strategic foundations of the school was the commitment of the school for innovation which I have found out during my observation in the school compound. The vision and mission statements have clearly stated the direction of the school for supporting innovation. Among the five core values identified, innovation was one of them, and this clearly indicates how much the school is working on creating organizational culture that encourages innovation.

A teacher named "Abebe" has pointed out that the educative and innovative organizational culture of the school has made some teachers miss the school after they left for different reasons. According to the respondent: "A teacher who left the school due to some personal reason has reported that he felt detached from the technologically embedded culture of the school; and, he is on the way to return though he earns better salary in his current working place".

Technological Infrastructure in Teaching and Learning Process

During my document analysis, I found out that there is a subject called STEM (Science, Technology, Engineering and Mathematics) which is given starting from grade one. On an interview session, a teacher has confirmed the role of the subject for supporting students' innovative inclinations. The project based STEM subject is given using a well-furnished workshop for all students at different grade levels. Once in a year, the school celebrates an innovation day so that the students can get the opportunity to present their projects in front of invited guests that include their parents and officials from Woreda, Kifle Ketema and City Administration. Despite positive responses given by research participants on the constructive contributions of the subject for students and my observation on different advanced project works made by students in the workshop, delivering a subject matter which is directly taken from foreign curriculum creates a critical concern that needs to be addressed (Sjøberg, 2002).

As the data gathered from interview shows, the school administration also closely follows students' academic achievements by making comparisons between results in continuous and summative assessments at the end of each term. The school makes co-integration analysis between these assessments using "PCGIVE" software. On this co-integration analysis, results fall between 0 and 1 . When assessment results are above 0.73 , it is assumed that the two types of assessments are meeting their expected goals. When analysis results are found to fall below 0.73 , they are assumed to reveal deviated results on students' achievements; and such incidences will be dealt 
thoroughly by involving all concerned stakeholders including home room teachers, subject teachers and parents.

According to the data gathered during the interview which was made with a deputy school director, the school has developed a three year school improvement program which has been cascaded from its five year strategic plan. To materialize the school improvement program, the school took different initiatives on improving its educational infra-structure. One of the evidences that justify how much the school took significant measures on modernizing the school's infra-structure was the use of interactive boards in all classrooms. For every class presentation, teachers are expected to prepare slip charts using laptops. Every flip chart is critically examined by subject matter experts and supervisors before class room presentations take place.

According to the discussion made with a school director, the school is actively working with like-minded schools found in USA to implement the "Harakness Table" educational practice in the future. As the school director stated: "This teaching methodology is a highly advanced approach that demands an in-depth training to capacitate teachers to a level at which they can facilitate inquiry based and advanced thinking practices. We know that such methodologies cannot happen in the near future; but we are highly committed to devote all necessary time and resources for its realization."

The existence of very fast Wifi service at all places in the school compound has also enabled teachers to serf abundant educational resources from the internet. I have also seen that all teachers are equipped with individual laptops starting from the day they joined the school. Though availing abundant internet access can support teachers' initiatives for searching educational resources from the internet, the absence of guideline for its proper usage could result in unintended results.

The ICT class is well equipped with modern desk-tops in a way that one desk top can be availed for one student. The ICT subject is given for all students at different grade levels based on minimum learning competencies which are prepared for each grade level. On the real time experience I had in the school, I observed how much students at early ages become familiar with ICT. As part of the interactive board educational approach, a school director has emphasized on their long run plan for transforming classroom education using reading palm-tops in the future by replacing the current printed educational materials for the students.

\section{Technology Supported Communication}

Active participation of all concerned stakeholders assures the overall academic improvement and psychosocial development of students. Sustainable communication between schools and parents plays grate role on unifying the concerted effort made by all educational stakeholders. For the last two and half years, the school has strictly used "Communication Book" which serves as a medium for bridging communications between home and school. As an institution that encourages technology driven approaches, the school has finalized all necessary preparations to implement ROBO technology for replacing communication books in the upcoming academic year. The application will be installed on smartphones of all parents so that all necessary 
academic and non-academic activities concerning their children can be reported on daily basis. The report includes daily continuous assessment results and their physical and psycho-emotional well-being through-out their stay in the school.

On the discussions made both with the two directors and one deputy school director, I have raised the issue of using social networking platforms like Whatsup, Telegram and viber for communications among stakeholders including parents, teachers and school administrators as far as there is a very fast internet connection (Zaideieh, 2012),. Having a strong conviction for implementing ROBO and Phedena soft wares in the future, at least for the time being, they have admitted that they have not so far made efforts to create communications through social networking platforms.

Along with the daily reports made for parents, daily classroom activities including continuous assessment assignments are sent to subject specific experts and quality assurance professionals. Using those reports, the two mentioned offices make sure the conformity of daily based classroom activities against the standard of the school. For deviations identified, consultation sessions are arranged to the teachers on areas for improvements. When consultation sessions fail to address the identified performance gaps, compiled reports will be sent to the deputy school director so that further improvement interventions can be arranged. As the data gathered from teachers show, due to its repeated and time taking nature, these daily basis communication between subject experts and teachers may need some kind of technological intervention in the future.

Improving School Management by Applying Contemporary Management Approaches

For the interview question that asked respondents about the experience of the school on adopting and adapting international quality assurance approaches including kaizen and quality management system, they have admitted that they are not that much familiar with international quality assurance practices which were mentioned during the interview sessions.. As the empirical data of the research indicates, the school so far has been categorized as the only level 4 educational institution in the metropolitan by meeting most of the quality assurance standards set by the Addis Ababa City Administration Education Office; but, has not yet introduced other international management standards or cultures.

\section{Capacity Building Initiatives}

According to the gathered qualitative data, at summer times, all teachers are expected to participate in a month long training program which is aimed at enhancing their in-service capacities. In addition to this, at entry level, new comer teachers become well acquainted with different technological platforms including the interactive board along with other pedagogical trainings. According to the data gathered during an interview session, staffing newly recruited teachers takes place in coordinated manner. Instead of being confined to oral and written exams, classroom based practical tests are conducted to make sure how much they are familiar with basic pedagogical and academic specific principles. Along with this, at different intervals, teachers are tested for improving their academic, pedagogical and language competencies. Based on identified 
training gaps during regular appraisal programs, they are catered with different trainings arranged in the school or other training institutions. Apart from class room based training arrangements, teachers are encouraged to engage in self-initiated trainings using different academic and pedagogical trainings which are available on U-tubes.

Educational Technology vs. Decision making

Based on the data gathered through interview, daily basis recording and reporting on students' academic progress using individualized lap tops has clearly facilitated proactive and collaborative decision making in the school. Apart from this, thirty minute debriefing sessions which are held every day in the morning at different management ladders helped to work on limitations on time. Regular face to face discussions and contacts made through communication books with parents have also increased parents' involvement on decisions made at school level. As per the comment given by a school director, though the school can even further introduce technology induced approaches in the future, pictorial and written communications made both for students in classrooms and teachers in the staff room on expectations and standards of the school has positively supported academic and administrative decisions made in the school.

\section{Educational Technology for Supporting Extracurricular Activities}

Apart from being included in the main curriculum of the school, STEM has created an opportunity for students with special inclination towards innovation to further participate in innovative extra- curricular activities. The STEM work shop remains open for such students to dedicate themselves on innovative activities at their break times. Students who have affiliations to music and art are engaged in their respective clubs. These clubs have their own rooms with all their furnished resources. The music club with all its digitalized modern and traditional instruments attracts students with special talents on the area. These students regularly practice different plays for school day programs. In addition to this, students who are good at literature and journalism actively participate in the mini-media club that broadcasts poems, essays and news at break times using modern sound system.

Educational Technology for Knowledge Management

Preserving and maintaining corporate level knowledge has become one of the critical challenges in the current dynamic world. The initiative taken by the school to stage morning debriefings on daily basis was considered as one of its endeavors to support knowledge management through organizational learning. Recording and communicating students' up-to-date performance among different experts in the school can also be taken as a good contribution for school management. Developing the school's documentary film was also one of the major steps taken for preserving the school's corporate knowledge. As it has been admitted by a school director through discussions made during an interview session, the school has identified its limitation on compiling corporate level knowledge and individual based knowledge management to minimize lost tacit and explicit knowledge during employees' turn over at individual level and when time elapses at company level. On one of the interview sessions, the issue of assigning one central office 
for compiling and preserving individual, departmental and company level knowledge was raised as one of the solutions to minimize fading away of corporate knowledge through time.

Benchmarking for Knowledge and Technology Transfer

Benchmarking can be taken as a deliberate engagement of an organization to bring best practices from other like-minded companies through experience sharing events. The data gathered through interview made with a deputy director has revealed that before delving into adopting best practices from like-minded organizations in the sector, the school has made in-depth analysis on educational management trends and practices in schools in different parts of the world. The study has specifically dwelt on making assessments on schools from North America, 29 outstanding schools from OECD countries, Far East countries and some selected schools in Qatar. In addition to this, a five year longitudinal cohort study was made on some selected students who managed to join different fields of study in Addis Ababa University. After taking best practices from the selected areas, the study team has arrived at two schools in USA namely Philips Exeler Academy and Plano high school. Accordingly, the school has adopted school curriculum, school organization and management practices along with their technological exposures from the two selected schools. On discussions made during the interview, though there are minor efforts made by the school on promoting indigenous knowledge and contextualization through worksheets given to students and making some trials to outsource its curriculum development program to experts from Addis Ababa University, implementing foreign based curriculum has been identified as one of the major shortcomings of the school.

Conclusion and Implications

As it has been elaborated in the Result and Discussion section of the study, the selected school has managed to introduce contemporary technological tools and methodologies which are mainly targeted at improving school management practices within very short period of time. The empirical qualitative data has shown that the school has gone a very long journey in terms of scaling up its School Improvement Program and; and in recognition of these tangible efforts (including its commitment for exercising modern technological approaches), Addis Ababa City Administration Education Bureau has granted the first level four certificate.

As it has been argued by different writers, technology driven initiatives by themselves cannot guarantee quality school management or teaching learning process in particular. Subject specific and socio-cultural studies on the compatibility of the induced technologies should have been a pre-requisite before their implementations (Stošić, 2015). As it has been proposed by Higgins (2012), technology driven educational interventions could bring about positive changes when they are utilized as supplementary instead of replacing the previously existing approaches. As far as the data collected through interview and observation clearly indicates, technologically driven educational system is underway in the selected school by replacing the previous traditional approaches in the absence of studies made on subject specific and socio-cultural contexts.

Giving much priority for the school's achievements on realizing high scores on school improvement program, both the city administration education bureau and the school have ignored 
the detrimental effects that could be incurred due to properly un-contextualized curriculum. Greater care need to be taken on modeling such schools as long as one of the major concerns in the education system of the land is relevance (Education and Training Policy, 1994)

The other critical issue that needs to be addressed in the future is affordability. Considering the term payment set by the school and the economic status of parents who send their children to the selected school, taking such schools as a model cannot help to expand their best practices since the technologies introduced might not be affordable by other schools in the city. In general terms, acknowledging positive contributions of the existing technological advancements in the school which has stayed in the sector for a very short period of time, it might be too early to determine its overall achievements. But, all concerned parties including parents, the education 
bureau and the school itself should reassess on how and why it has been engaged in following technology driven education through deliberate and in-depth studies in the future.

\section{References}

Abdo, M., \& Semela, T. (2010). Teachers of Poor Communities: The Tale of Instructional Media Use in Primary Schools of" Gedeo" Zone, Southern Ethiopia. Australian Journal of Teacher Education, 35(7), 78-92.

Adam, L. (2007, April). Information and communication technologies, knowledge management and indigenous knowledge: Implications to livelihood of communities in Ethiopia. In a Workshop on" The Role of ICT in Preserving and Disseminating Indigenous Knowledge", Addis Ababa.

Afshari, M., Abu Bakar, K., Su Luan, W., Abu Samah, B. \& Say Fooi, F. (2008). School Leadership and Information Communication Technology, The Turkish Online Journal of Educational Technology, 7(4), 82-91.

Asgedom, A. (1999). Availability and use of instructional materials in Tigray primary schools. IER flambeau, 7(1), 53-66.

Bitew, G. D. (2008). Using 'plasma TV' broad casts in Ethiopian secondary schools: a brief survey. Australasian Journal of Educational Technology, 24(2), 150-167.

Chapman, D. W., \& Mahlck, L. O. (2004). Adapting Technology for School Improvement: A Global Perspective. International Institute for Educational Planning (IIEP) UNESCO. 7-9 rue Eugene-Delacroix, 75116 Paris, France.

Chaulk, C., \& Haché, G. (2009). Role of Technology in Education. 
Cloete, A.L., 2017, 'Technology and education: Challenges and opportunities', HTS Teologiese Studies/ Theological Studies 73(4), a4589. https://doi.org/ 10.4102/hts.v73i4.4589

Cohen, D. K. (1987). Educational technology, policy, and practice. Educational evaluation and policy analysis, 9(2), 153-170

Courville, K. (2011). Technology and Its Use in Education: Present Roles and Future Prospects. Online Submission.

Dawson, C. \& Rakes, G. C. (2003). The Influence of Principals' Technology Training on the Integration of Technology in Schools. Journal of Research on Technology in Education, 36(1), 2949

Dogan, S. (2010). PERCEPTIONS OF TEACHERS ABOUT THE USE OF EDUCATIONAL TECHNOLOGIES IN THE PROCESS OF INSTRUCTION. Educational Sciences/Odgojne Znanosti, 12(2).

Gibson, S., Moline, T., \& Dyck, B. (2011). What Are Education Students' Perceptions of the Role of Technology in Social Studies Pedagogy?. Alberta Journal of Educational Research, 57(1), 7387.

Higgins, S., Xiao, Z., \& Katsipataki, M. (2012). The impact of digital technology on learning: A summary for the education endowment foundation. Durham, UK: Education Endowment Foundation and Durham University.

Hylén, J. (2006). Open educational resources: Opportunities and challenges. Proceedings of Open Education, 4963.

Klopfer, E., Osterweil, S., Groff, J., \& Haas, J. (2009). Using the technology of today in the classroom today: The instructional power of digital games, social networking, simulations and how teachers can leverage them. The Education Arcade, 1, 20.

Kumpulainen, K. (2007). Educational technology: Opportunities and challenges. Oulu University Press.

Lazar, S. (2015). The importance of educational technology in teaching. International Journal of Cognitive Research in Science, Engineering and Education, 3(1).

Mayes, R., Natividad, G., \& Spector, J. (2015). Challenges for educational technologists in the 21st century. Education Sciences, 5(3), 221-237.

Murray, C. "Curriki offers new world of course content. eSchool News. Retrieved June 1, 2009." (2007). 
Osam, I. (2016). Managing the Role of Science and Technology Education Programs in Promoting Enterprises for National Development in Nigeria. International Journal of Scientific Research in Education, 97.

Otara, A. (2012). The future of education and its challenges in Africa. International Journal of Humanities and Social Science, 2(9), 151-156.

Sarfo, F. K., \& Ansong-Gyimah, K. (2010). The Perceptions of Students, Teachers, and Educational Officers in Ghana on the Role of Computer and the Teacher in Promoting the First 
Five Principles of Instruction. Turkish Online Journal of Educational Technology-TOJET, 9(3), 85-95.

Schleicher, A. (2006). Where immigrant students succeed: a comparative review of performance and engagement in PISA 2003: C) OECD 2006. Intercultural Education, 17(5), 507-516.

Sjøberg, S. (2002). Science and technology education: Current challenges and possible solutions. Innovations in science and technology education, 8, 296-307.

Stošić L. (2015). The importance of educational technology in teaching. College of professional studies educators, Aleksinac Serbia

Strecker, S., Kundisch, D., Lehner, F., Leimeister, J. M., \& Schubert, P. (2018). Higher education and the opportunities and challenges of educational technology. Business \& Information Systems Engineering, 60(2), 181-189.

Tearale, P. (2003) ICT Implementation: What Makes the Difference? British Journal of Educational Technology, 34(5), 567-583.

Transitional Government of Ethiopia. (1994). Education and training policy(ETP).Addis Ababa: Education Materials Production and Distribution Agency.

US Department of Education. (2017). Reimagining the role of technology in education: 2017 national education technology plan update.

Watson, D. (2006). Understanding the relationship between ICT and education means exploring innovation and change. Education and Information Technologies, 11(3-4), 199-216.

Woldab, Z. E. (2014). E-Learning technology in pre-service teachers training-lessons for Ethiopia. Journal of Educational and Social Research, 4(1), 159.

Zaidieh, A. J. Y. (2012). The use of social networking in education: Challenges and opportunities. World of Computer Science and Information Technology Journal (WCSIT), 2(1), 18-21. 